\title{
Histoarchitecture of Large Intestine and Lympho Glandular Complex of Pig
}

\author{
K.B. Dev Choudhury, M. Sarma
}

10.18805/IJAR.B-4772

\begin{abstract}
Background: To have a better understanding of the lympho glandular complexes (LGC) along with the histoarchitecture of large intestine and associated $\mathrm{M}$ cells, the proposed study have been undertaken.

Methods: Present study was conducted on 12 (twelve) numbers of apparently healthy weaned crossbred piglets of 3 to 4 months irrespective of sex. After humane sacrifice of the animals with the approval of institutional animal ethics committee, the representative tissue samples were collected preserved, processed and stained as per standard methods of Luna (1968).

Result: Columnar cells predominated the follicle associated epithelium (FAE) and the crypts. $M$ cells were recorded in the follicle associated epithelium as well as in lower crypt epithelium in toluidine blue stained ultra thin sections. M cells were observed with intraepithelial lymphocyte and basally placed euchromatic nucleus. In the colon and rectum of crossbred pigs the lympho glandular complex (LGC) typically consisted of a pore like depression on surface epithelium from which extensions of mucosal glands passed through the circular gap into lamina muscularis mucosae. The lymphatic aggregation of LGC in the lamina propria and tunica submucosa showed three distinct zone viz. follicle, interfollicular area and dome area and distinct FAE could be appreciated. The epithelium lining the solitary lymphatic nodule (SLN) showed (Periodic acid-Schiff) PAS positive reaction. The mucous substance showed strong reaction in the gland in LGC and the FAE epithelium the number of goblet was less. The LGC was formed by aggregation of lymphoid follicles with invagination of crypt gland inside the follicle in the tunica sub mucosa. The follicle associated epithelium devoid of goblet cells were observed on the LGC with interspersed of diffuse migrating lymphocytes in the lamina propria. In the LGC, secondary follicle with interfollicular area was appreciated. In mesenteric lymph node the secondary follicles with inner germinal centre and outer corona could be seen in cortico medullary area. Meshwork of reticular fibers was abundantly present around the crypts in the lamina propria and in the pore like depression of LGC and around the secondary follicle. Collagen fibers could be seen surrounding the LGC and glands. Scanty collagen fibres were observed in the inter-follicular glands. Innervations of nerve fibre was observed around the lymphoid follicle and penetrating the LGC. The mucosal glands were PAS positive.
\end{abstract}

Key words: FAE, Histoachitecture, Large intestine, LGC, M cell, Pig.

\section{INTRODUCTION}

The epithelia and the $\mathrm{M}$ cells overlying the mucosal surfaces of the gastrointestinal tract specially the lymphoglandular complexes of large intestine are exposed to a great variety of microbial antigens. The host microflora interactions occur in the gut-associated lymphoid tissues (GALT), including the mesenteric lymph nodes (MLNs). The process of transcytosis mediated by $M$ cells, starts at the apical membrane of follicle associated epithelium. Endocytic vesicles are then trafficked across the thin cytoplasm of the $\mathrm{M}$ cells. Their contents are then released by exocytosis from the basolateral membrane, mainly to an infolded membrane domain that forms a pocket (Moue et al., 2008).

The gut associated lymphoid tissue is formed by Peyer's patches in the small intestine and isolated or solitary lymphoid nodules in large intestine (Nickel et al., 1996 and Frappier, 2007).

The gut mucosal surfaces form a mechanical barrier that separates the host from the external environment and they may be involved in the first-line of defence against luminal factors including pathogenic or non-pathogenic organism.

To have a better understanding of the lympho glandular complexes (LGC) along with the histoarchitecture of large
Department of Anatomy and Histology, College of Veterinary Science, Assam Agricultural University, Guwahati-781022, Assam, India

Corresponding Author: K.B. Dev Choudhury, Department of Anatomy and Histology, College of Veterinary Science, Assam Agricultural University, Guwahati-781 022, Assam, India.

Email: kamal.b.devchoudhury@aau.ac.in

How to cite this article: Choudhury, K.B.D. and Sarma, M. (2022). Histoarchitecture of Large Intestine and Lympho Glandular Complex of Pig. Indian Journal of Animal Research. DOI: $10.18805 /$ IJAR.B-4772.

Submitted: 14-09-2021 Accepted: 09-12-2021 Online: 03-03-2022 intestine and associated M cells, the proposed study have been undertaken.

\section{MATERIALS AND METHODS}

Present study was conducted for a period of three years in Department of Veterinary Anatomy and Histology, CVSc, AAU, Khanapara. The experiment was designed on 12 (twelve) numbers of apparently healthy weaned crossbred piglets of 3 to 4 months irrespective of sex. The piglets were procured from different areas of Kamrup district and quarantined in the departmental animal shed. 
The experimental animals were properly dewormed and maintained under same standard manage mental protocol before experiment. After humane sacrifice of the animals with the approval of institutional animal ethics committee, (Approval No. 770/ac/CPCSEA/ FVSC/AAU/IAEC/17-18/488 dated 09.08.2017) the representative of large intestine, solitary lymphoid nodule tissue samples and mesenteric lymph nodes were collected from the large intestine, preserved in 10\% Neutral Buffered Formalin (NBF), processed and stained as per standard methods of Luna (1968) as under-

a. Mayer's Haematoxylin and Eosin staining.

b. Van Gieson's method for collagen fibres.

c. Verhoeff-van gieson method for elastic fibres (http:// www.ihcworld.com/_protocols/special_stains/vvg.htm).

d. Gomoris method for reticular fibres.

e. Bielschowsky's method for axis cylinder and dendrites.

f. Toluidine blue stain for $M$ cell in ultra thin sections.

Then the stained slides were examined under Nikon $80 \mathrm{i}$ microscope with image analysing and micrometry software.

\section{RESULTS AND DISCUSSION}

In the present study, the wall of large intestine was comprised of four layers typical to the histo-architecture of hollow organs viz. tunica mucosa, tunica sub-mucosa, tunica musculosa and tunica serosa which was in accordance with Banks (1986). The solitary lymphatic nodules (SLN) and lymphoglandular complexes (LGCs) were observed in the tunica submucosa of colon and rectum. The SLN was a well demarcated encapsulated lymphocytic aggregation but LGC consisted of partially encapsulated lymphocytic aggregate (Fig 1). Variable numbers of lymphatic nodules with germinal centres were observed in the tunica submusoca. The surface epithelial lining of LGC of large intestine showed invagination into the follicular complex and the inter nodular lymphoid tissue were penetrated by the mucosal gland from the tunica mucosa (Fig 2) which was similar to the findings of Morfitt and Pohlenz (1989) in porcine.

In the colon and rectum of crossbred pigs the LGCs typically consisted of a pore like depression on surface epithelium from which extensions of mucosal glands passed through the circular gap into lamina muscularis mucosae and penetrated submucosal lymphoid tissue (Fig 2). This might be an access route of gut antigens to the lymphog landular complex. The present findings was in consonance with the findings of Kapoor and Singh (2016) in buffalo calves. However, in some LGCs no pore like depression and disrupted muscularis mucosae could be observed. The muscularis mucosae layer distinctly separated the SLN and

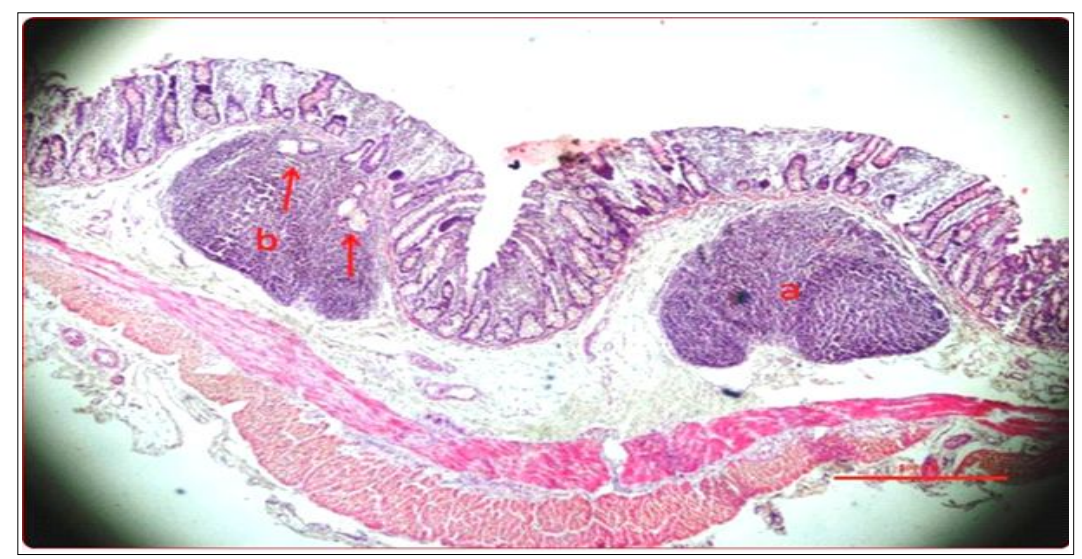

Fig 1: Photomicropgraph of colon showing SLN (a) and LGC (b) with intra nodular gland (red arrow) (H\&E, X40).

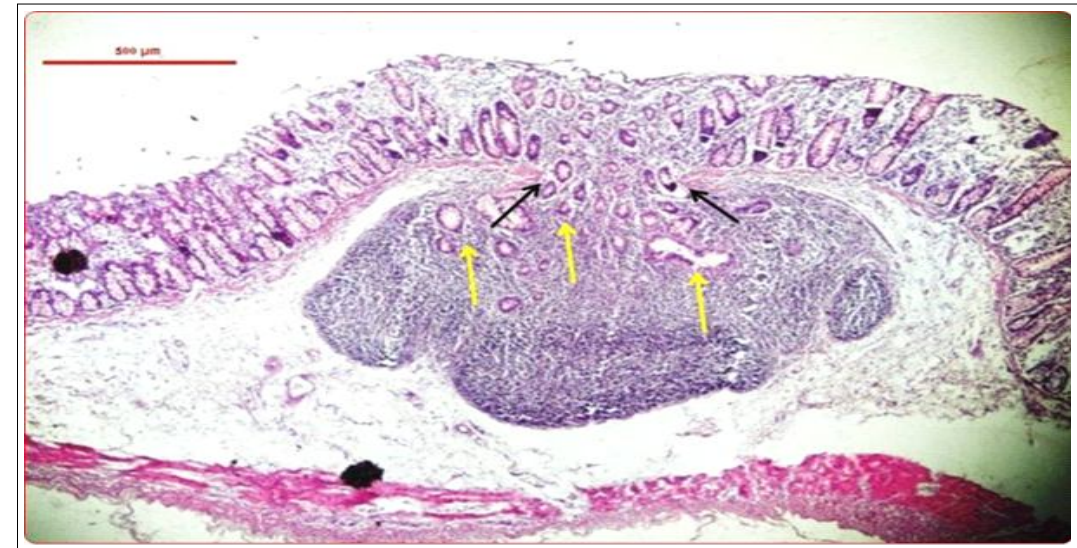

Fig 2: Photomicropgraph of colon showing flask shaped LGC with disintegration of lamina Musculasis Mucosae (black arrow) and gland (yellow arrow), (H\&E, X100). 
LGC from the luminal side (Fig 1). This might be due to faviform type of LGC. The present findings were not in agreement with the findings of Zhaxi et al. (2014) in Bactrian Camels, Gautam et al. (2013) in goat and Morfitt and Pohlenz (1989) in porcine.

The lymphatic aggregation of LGC in the lamina propria and tunica submucosa showed three distinct zone viz. follicle, interfollicular area and dome area (Fig 3) and distinct FAE could be appreciated in the absorptive epithelium and crypts in the submucosa. Occasionally the rectal LGC was observed as one distinct lymphoid follicle that was surrounded by a glandular epithelium (Fig 4).

In the present study, the mesenteric lymph node associated with the large intestine was covered by

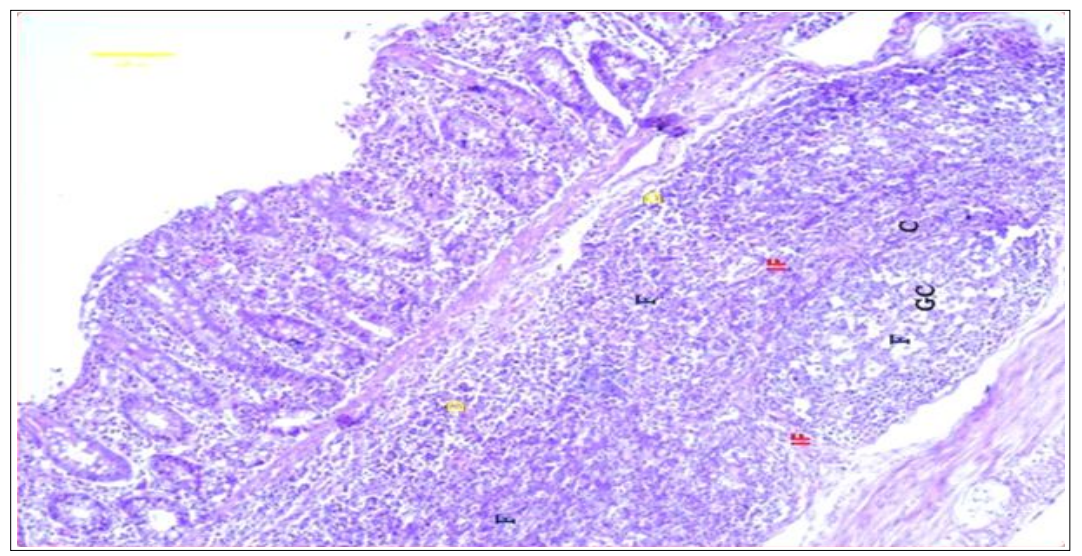

Fig 3: Photomicropgraph of rectum showing distinct follicle $(F)$ with outer corona $(C)$ and inner germinal centre $(G C)$ inter follicular area (IF), (H\&E, X100).

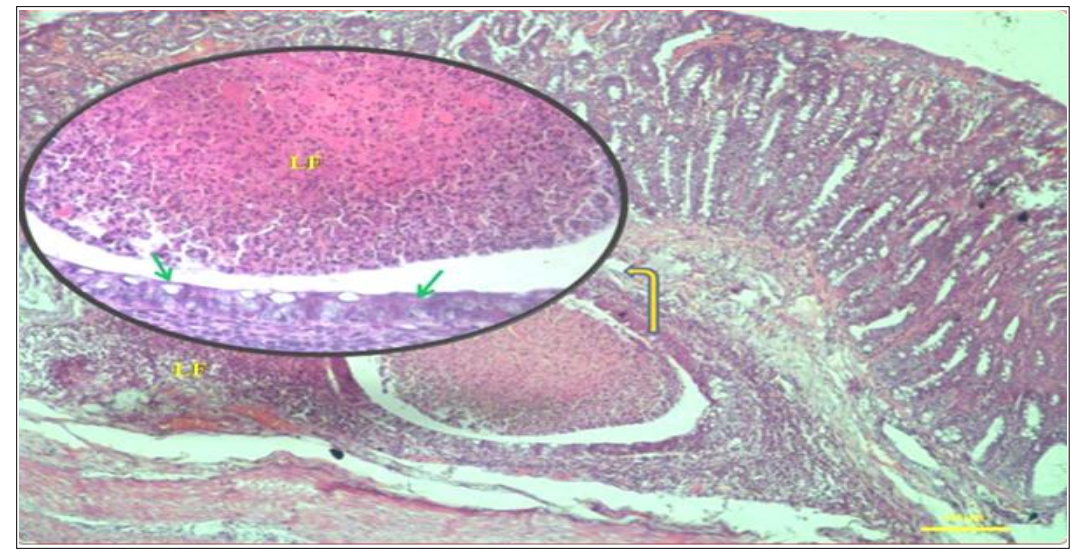

Fig 4: Photomicropgraph of colonic LGC showing lympoid follicle completely surrounded by glandular epithelium (yellow arrow), (H\&E, X100).

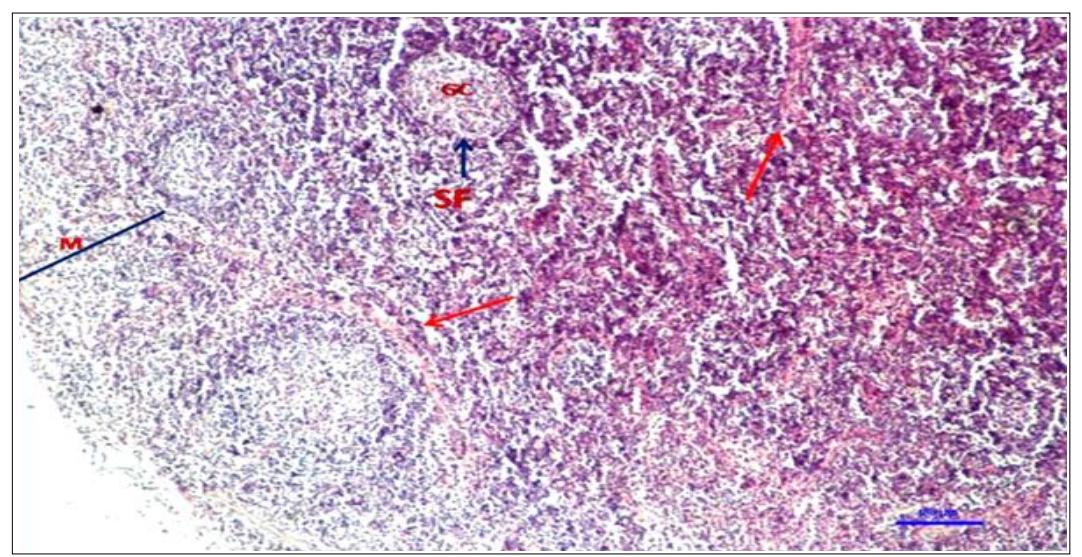

Fig 5: Photomicropgraph of mesenteric lymph node showing medulla (M) secondary follicle (SF), germinal centre (GC), trabeculae (red arrow), (H\&E, X100). 
connective tissue capsule with distinct cortex and medulla. Distinct secondary lymphoid follicle with inner germinal centre and outer corona could be seen in cortico-medullary area (Fig 5). However, Kalita et al. (2014) reported that the lymph nodes of Mizo pigs consisted of cortex like tissue and medulla like tissue.

The connective tissue covering the SLN and LGC was well appreciated and scanty collagen fibres (Fig 6) were observed in the inter-follicular glands, which was not in agreement with the findings of Kapoor and Singh (2016) in buffalo calf. The reticular fibres were present on the outer cortical area of the follicles and in the inter follicular areas. Similar findings were also reported in pig by Dev Choudhury et al. (2017). In the present study, nerve fibre innervations were seen around the crypt area, lamina propria, and tunica sub mucosa of large intestine. A fine network of nerve fibres

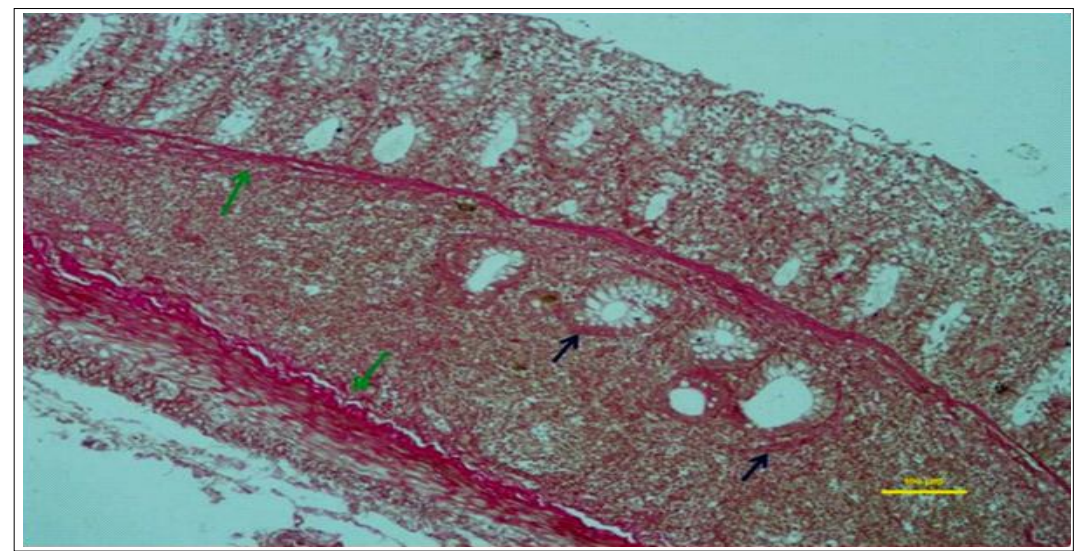

Fig 6: Photomicropgraph of showing the SLN of rectum covered with collagen fiber (green arrow) and interfollicular gland surrounded by collegen fibre (blue arrow), (H\&E, X100).

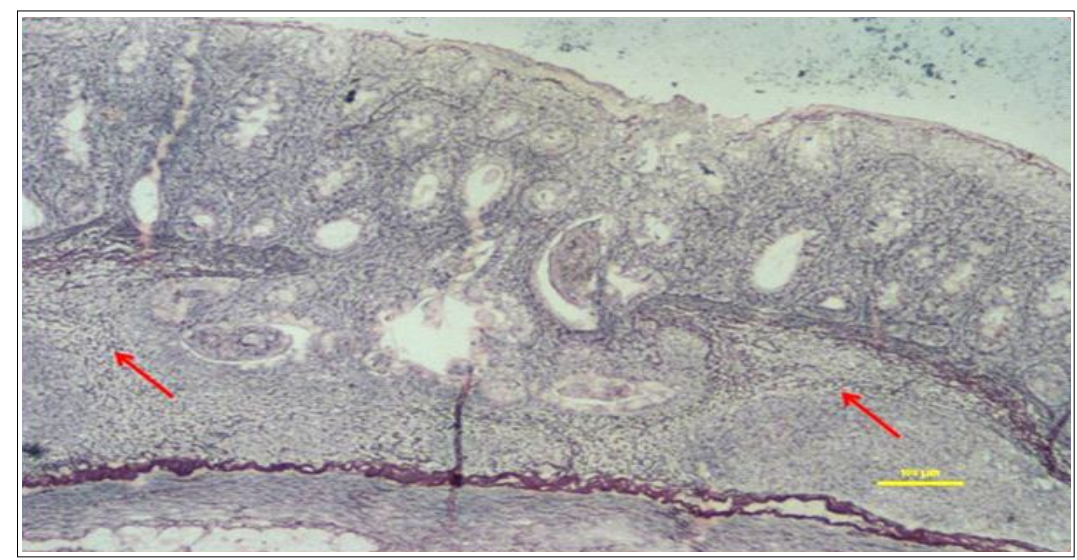

Fig 7: Photomicropgraph of colon showing innervations of nerve fibres around the lymphoid follicle (red arrow), (biel schowslery stain, X100).

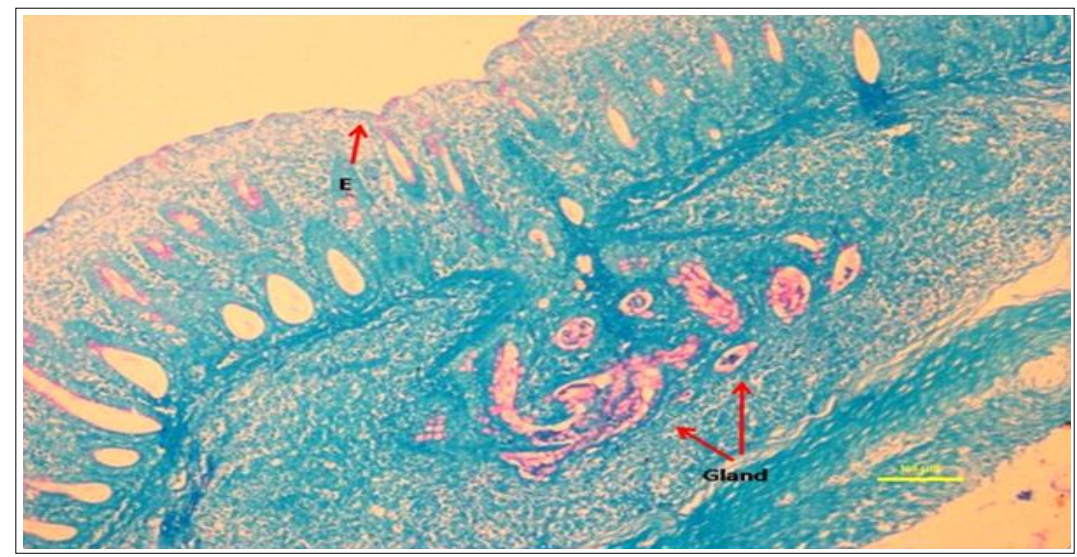

Fig 8: Photomicropgraph of colon showing strong PAS positive reaction in absoptive epithelium (E) and gland in LGC, (PAS alcian blue, $\mathrm{X} 100$ ). 
was also observed around the lymphoid follicle and observed penetrating the LGC (Fig 7).

In the present investigation FAE and sub epithelial dome (SED) were appreciated in semi thin sections stained with toluidine blue. In rectal LGC distinct FAE could be seen. However, Gautam (2015) in piglet reported that distinct FAE was absent in LGC. Presence of germinal centres in LGC were observed in the tunica submucosa. Disrupted lamina muscularis mucosae could also be observed (Fig 2) which was in consonance with the findings of Bayraktaroglu et al. (2016) in Angora goat.
The epithelium lining the SLN showed PAS positive reaction. The mucous substance showed strong reaction in the gland in LGC (Fig 8). Again, the PAS stained sections (Fig 9) revealed that in the FAE epithelium, the number of goblet was less. Frappier (2007) also opined that in the FAE there were less number of goblet cell and more number of $M$ cells. This might be due to the transport of antigen through $\mathrm{M}$ cell to the underlying dome area from the FAE.

Columnar cells predominated the FAE and the crypts. Abundant goblet cells were present in the crypt epithelium.

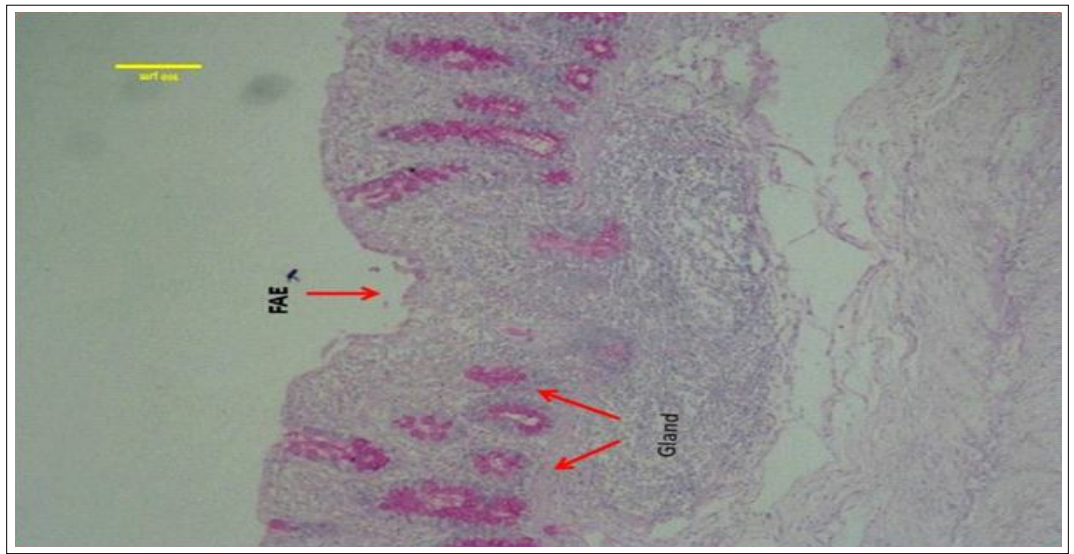

Fig 9: Photomicropgraph of rectum showing fae with less goblet celi, (Mcmanus method, X100).

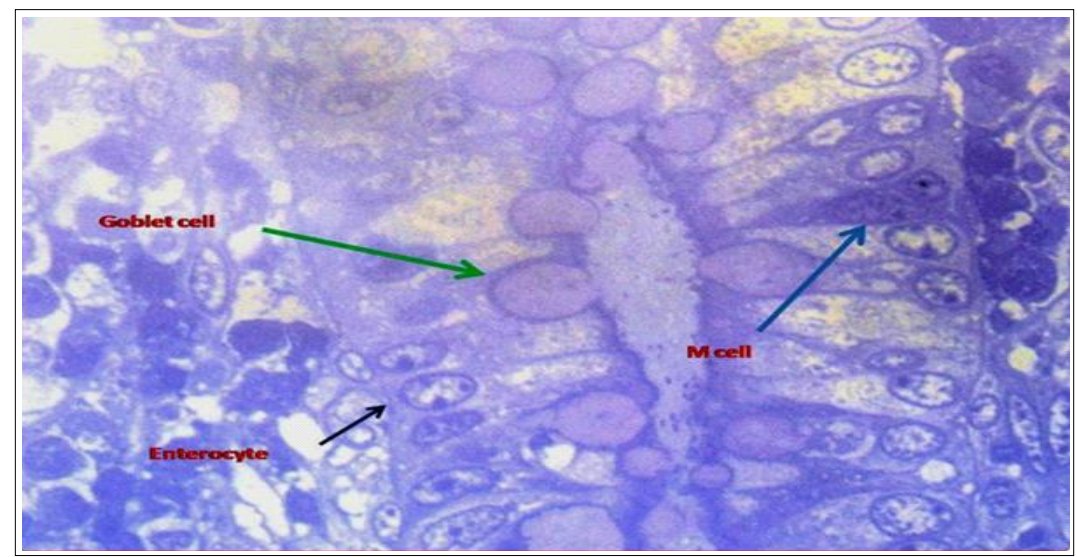

Fig 10: Photomicropgraph of semi-thin section of colon showing $\mathrm{M}$ cell, goblet cell and entrocyte in lower crypt, (toluine blue, X1000).

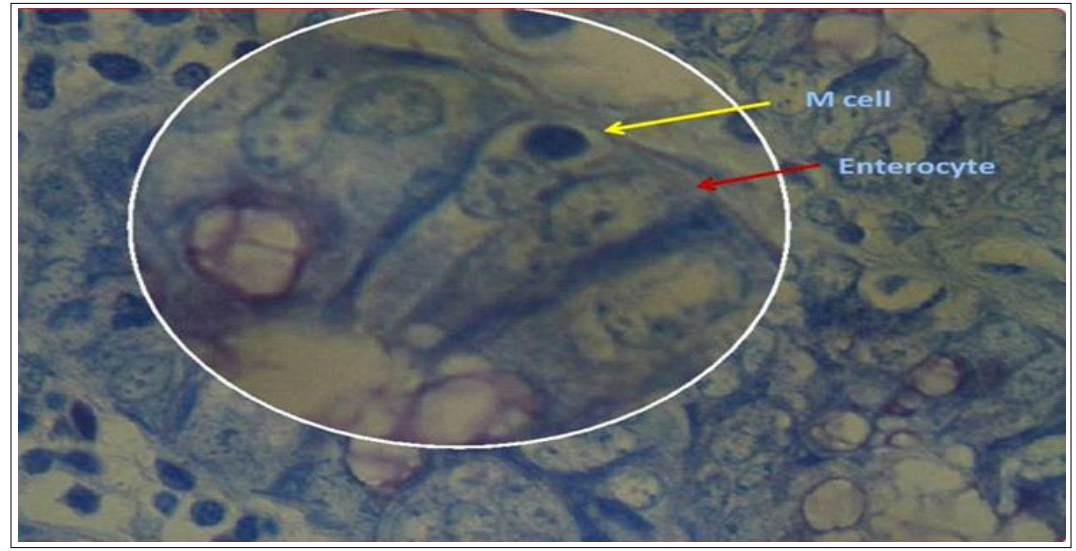

Fig 11: Photomicropgraph of semi-thin section of rectum showing $M$ cell and enterocyte, (toluidine blue, $X 100$ ). 
The $M$ cells showed presence of inter epithelial lymphocyte and basally placed heterochromatic nucleus. However, Owen (1999) opined that M cells of humans, rodents and chickens contained basolateral pockets where migrating lymphocytes and macrophages were present. The enterocytes were distinct with round to oval euchromatic nucleus (Fig 10 and 11). Beyaz et al. (2010) in Angora rabbit reported that $M$ cells were observed with intraepithelial lymphocyte and basally placed euchromatic nucleus similar to the present findings.

\section{ACKNOWLEDGEMENT}

The authors are grateful to honourable Director of $P G$ Studies, Assam Agricultural University and Dean, C.V.Sc., AAU, Khanapara for providing necessary facility to carry out part of our Research work and the members of the advisory committee.

\section{Conflict of interest: None.}

\section{REFERENCES}

Banks, W.J. (1986). Applied Veterinary Histology. $2^{\text {nd }}$ Edn., Williams and Wilkins, Los Angeles. pp. 405-410.

Bayraktaroglu, A.G., Ozbek, M., Kurtdede, N., Altunay, H., Ergun, L., Ergun, E. and Asti, R.N. (2016). Histological structure of the colonic lymphoglandular complex in the Angora goat. Journal of the Turkish Veterinary Medical Society. 87: 24-33.

Beyaz, F., Ergun, E., Bayraktaroglu, A.G. and Ergun, L. (2010). The identification of intestinal $M$ cells in the sacculus rotundus and appendix of the Angora rabbit. Veterinary Research Communications. 34: 255-265.

Dev Choudhury, K.B., Sarma, M., Talukdar, M., Gautam, C.K., Barman, N.N. and Deka, A. (2017). Anatomy of solitary lymphoid nodules in large intestine of post weaned pigs. International Journal of Chemical Studies. 5(2): 510-512. 5: $510-512$.

Frappier, B.L. (2007). Dellmann's Textbook of Histology. Dellmann's Textbook of Veterinary Histology. $6^{\text {th }}$ Edition. Blackwell Publishing, Asia. pp 194-201.

Gautam, C.K. (2015). Antigen uptake and comparative histo morphology and ultrastructure of the histocompertments of Peyer's patches and solitary lymphoid nodules of intestine of growing piglet. Ph.D. Thesis, Assam Agricultural University, Jorhat.
Gautam, C.K., Talukdar, M., Sarma, K., Sarma, S., Barman, N.N. and Baishya, G. (2013). Distribution and histomorphology of solitary lymphoid nodules of large intestine in indigenous goat of Assam (Capra hircus). Indian Vet. J. 90 (8): 18-20. Indian Veterinary Journal. 90: 18-20.

Kalita, A., Kalita, P.C. and Doley, P.J. (2014). Light Microscopic Study on the Peripheral Lymphnodes of Mizo Local Pig (Zo Vawk). Asian Journal of Biomedical and Pharmaceutical Sciences. 4(28): 7-12. Asian Journal of Biomedical and Pharmaceutical Sciences. 4: 7-12.

Kapoor, K. and Singh, O. (2016). Histoenzymic Distribution in Ileal Peyer's Patches of Buffalo during Prenatal Development. Journal of Animal Research. Journal of Animal Research. 6(4): 677-683.

Kapoor, K. and Singh, O. (2016). Lymphoglandular Complexes in Proximal Colon of Buffalo Calves (Bubalus bubalis). International Journal of Morphology. 34: 1137-1141.

Luna, L.G. (1968). Manual of Histologic Staining Methods of Armed Forces Institute of Pathology. $3^{\text {rd }}$ edn. McGraw Hill Book Company, New York.

Morfit, D.C. and Pohlenz, J.F.L. (1989). Porcine colonic lymphoglandular complex; distribution, strecture and epithelium. The American Journal of Anatomy., 184: 41-51.

Moue, M., Tohno, M., Shimazu, T., Kido, T., Aso, H., Saito, T. and Kitazawa, H. (2008). Toll-like receptor 4 and cytokine expression involved in functional immune response in an originally established porcine intestinal epitheliocyte cell line. Biochimica et Biophysica Acta. 1780: 134-144.

Nickel, R., Schmmur, A. and Seiferle, E. (1996). The Viscera of Domestic Mammels. $2^{\text {nd }}$ Edn. Verlag Paul Parey, Berlin, Hamburg, Blackwell Publishing. pp. 101-194.

Owen, R.L. (1999). Uptake and transport of intestinal macro molecules and microorganisms by M cells in Peyer's patches- A personal and historical perspective. Seminars in Immunology. 11: 157-163.

Zhaxi, Y., Wang, W., Zhang, W., Gao, Q., Guo, M. and Jia, S. (2014). Morphologic observation of mucosa-associated ymphoid tissue in the large intestine of bactrian camels (Camelusbactrianus). The Anatomical Record. 297: 12921301. 